\title{
The importance of quantifying food waste in Canada
}

\author{
Majd Abdulla ${ }^{a}$ \\ University of British Columbia \\ Ralph C. Martin ${ }^{\text {b }}$ \\ University of Guelph \\ Martin Gooch ${ }^{\mathrm{c}}$ \\ Value Chain Management International \\ Eduardo Jovel ${ }^{\mathrm{d}}$ \\ University of British Columbia
}

Submitted January 6, 2012 / Revised April 19, June 28, July 17, October 19, December 18, 2012;

January 6, 2013 / Accepted January 9, 2013 / Published online April 1, 2013

Citation: Abdulla, M., Martin, R. C., Gooch, M., \& Jovel, E. (2013). The importance of quantifying

food waste in Canada. Journal of Agriculture, Food Systems, and Community Development, 3(2), 137-151.

http://dx.doi.org/10.5304/jafscd.2013.032.018

Copyright (C) 2013 by New Leaf Associates, Inc.

a Majd Abdulla, Honorary Research Associate with Land and

Food Systems, University of British Columbia, Vancouver, British Columbia, Canada.

Majd Abdulla is now a private consultant on food systems, food security, and sustainable agriculture.

b Ralph C. Martin, Professor, Loblaw Chair in Sustainable Food Production, University of Guelph, Guelph, Ontario, Canada; rcmartin@uoguelph.ca

c Martin Gooch, Chief Executive Officer, Value Chain Management International, Ontario, Canada; martin@,vcminternational.com

d Eduardo Jovel, Faculty of Land and Food Systems, University of British Columbia, Vancouver, British Columbia, Canada; ejovel@interchange.ubc.ca

* Corresponding author: Majd Abdulla, 9505 Boulevard Gouin, Apartment \#203, Pierrefonds, Quebec H8Y 1T7 Canada; +1-514-294-8692; midabdulla@gmail.com

Note: This paper was presented at the Sixth Annual Meeting of the Canadian Association for Food Studies (CAFS), May 2831, 2011, in Fredericton, New Brunswick, Canada.

\begin{abstract}
Understanding food waste in Canada may offer previously unrecognized opportunities and strategies to address rising food-cost inflation, food insecurity, and negative ecological impacts and energy costs attributable to food production, distribution, and accessibility. It is significant for all agents along the food chain and policy makers to know how much food Canadians waste, as well as why and where. This paper examines food waste at both the consumer and retailer levels. We used data from reports published by Statistics Canada and the World Bank to calculate the amount of food waste from the food available for consumption from 1961 to 2009. The preliminary results of the research show that food waste increased over time in relation to the food available for consumption. The average food waste was estimated at 40 percent of food available for consumption over almost five decades. The conclusion can also be
\end{abstract}


drawn that food waste is positively correlated with per capital GDP and per capita income. We present recommendations for quantifying food waste and understanding the combination of reasons and factors that drive up food waste.

\section{Keywords}

Canada, energy waste, food waste, quantifying food waste

\section{Introduction}

Awareness of food waste and its impact on the economy and the environment is growing nationally and globally (Food and Agriculture Organization of the United Nations [FAO], n.d.; Parfitt, Barthel and Macnaughton, 2010). This interest is being triggered directly by factors such as soaring food prices (Monier et al., 2010), greenhouse gas (GHG) emissions from agriculture (Garnett, 2010), and world hunger and increasing global food insecurity (Broughton et al., 2006; FAO, 2005; Kerstetter \& Goldberg, 2007; Parfitt et al., 2010; UK Department of International Development [UK DFID], 2004). Yet surprisingly little research is being conducted into how much food is wasted and why (Gustavsson, Cederberg, Sonesson, Van Otterdijk, \& Meybeck, 2011), particularly since reducing the wastage of food already produced is the more appropriate option for feeding a growing population and lessening the agri-food industry's impact on the environment (Gooch, Felfel, \& Marenick, 2010). The UK's Waste Resources and Action Program (WRAP), which sponsors the "Love Food, Hate Waste" website, estimated that if food that is currently wasted were eaten in the UK (5.3 million tons or 60 percent of 8.3 million tons annually), it would have the same carbon impact as taking five million cars off their roads (WRAP, 2011). This 5.3 million tons of food waste required 6.2 billion cubic meters of water to be produced, which is 6 percent of the UK's water requirements and nearly twice the annual household water usage of the UK (WRAP, 2011).

The International Water Management Institute (IWMI) showed that the amount of food produced on farms is much greater than what is necessary for a healthy, productive, and active life for the global population (Lundqvist, de Franiture, \& Molden, 2008). Nevertheless, world hunger persists, and the costly investments made to mitigate it have been insufficient. This conflict can be partially explained by the significant amount of food waste from farms to the household level (Lundqvist et al., 2008). It is estimated that 50 percent of the world's food ends up as losses and wastage from field to fork (Lundqvist et al., 2008). Lundqvist et al. (2008) recognized that not all agricultural production that does not reach our tables is wasted. The residue and some of the agricultural produce are used for animal feed, bio-energy, and soil amelioration. Food waste from field to fork takes place during harvesting, processing, distributing, storage, and transportation, as well as at the wholesale, retail, and household levels, and in other forms of agriculture production, such as bio-energy (Lundqvist et al., 2008). According to a recent report by Gustavsson et al. (2011), one-third (1.3 billion tons) of food produced or available globally for buman consumption only is wasted annually. Given the current system of food production, distribution, and consumption, meeting the growing demand for food could be a challenge.

In Canada, food waste was valued by Gooch et al. (2010) at CAD27 billion annually. This equaled 2 percent of Canadian GDP (Macdonald, 2009; Statistics Canada, 2009), and exceeded the amount that Canadians spent on dining out in 2009 (Gooch et al., 2010). The share of food wasted was approximately 40 percent of all food produced in Canada (Gooch et al., 2010). It is important to recognize that the environmental cost of high levels of GHG emission, such as carbon dioxide $\left(\mathrm{CO}_{2}\right)$ and methane $\left(\mathrm{CH}_{4}\right)$, is not included in this estimate (Gooch et al., 2010).

The largest contributor to food waste along the food chain is the consumer (Gooch et al., 2010; Griffin, Sobal \& Lyson, 2009). More than 50 percent of the estimated CAD27 billion worth of waste that ends up at landfills came from Canadian homes (Statistics Canada, 2010a). In total, solid food waste in 2007 was estimated to be six million tons between retailers' and consumers' plates (Gooch et al., 2010; Statistics Canada, 2009). Liquid waste was estimated to be 740 gallons (2.8 billion liters), including milk products, coffee, 
tea, soft drinks, and juices. These solid and liquid loss estimates do not include waste at the production and processing levels (Gooch et al., 2010).

Segregating the magnitude of food waste at each point in the food supply chain is a wise place to start, yet this is a global problem for which answers to the following question have been few: "How much food is lost and wasted in the world today and how can we prevent food losses?" (Gustavsson et al., 2011, p. 1). Canada, like the rest of the world, does not have the data required to empirically quantify food waste at each point in the food supply chain, from farmers to consumers. If there were increased understanding of the type and magnitude of food waste at each point, policy makers might be in a better position to evaluate the underlying causes of food waste in the Canadian food system and to consider preventive tools. In this paper, we extrapolate the quantity of food waste using secondary data from Statistics Canada over a 48year period (1961-2009). We also analyze the variation in food waste by food category and over time. With data relating to food waste primarily being found at the consumer and retailer points in the food chain, we point out the great need to quantify food waste holistically.

We supplemented the lack of detailed data for analyzing food waste in Canada by proposing a methodology to carry out this research. Recommendations have been made for further research. We hypothesize that quantifying food waste will result in increasing the awareness of food waste and food habits in terms of purchasing and eating. This, in turn, will result in reducing food waste and significantly increasing food security, improving food quality, achieving a cleaner environment, building a healthier economy, and, ultimately, sustaining communities and society (figure 1).

\section{Conceptual Framework and Methodology}

Two phenomena are taking place in the Canadian food system: a substantially high percentage of food waste (Gooch et al., 2010; Statistics Canada, 2009), and an increase in food consumption. The Canadian diet has changed since 1989 to include more fruit, vegetables, fish, nuts, cereals, and

\section{Figure 1. A Holistic Understanding of the Benefits of Quantifying Food Waste and Creation of a More Sustainable Society}

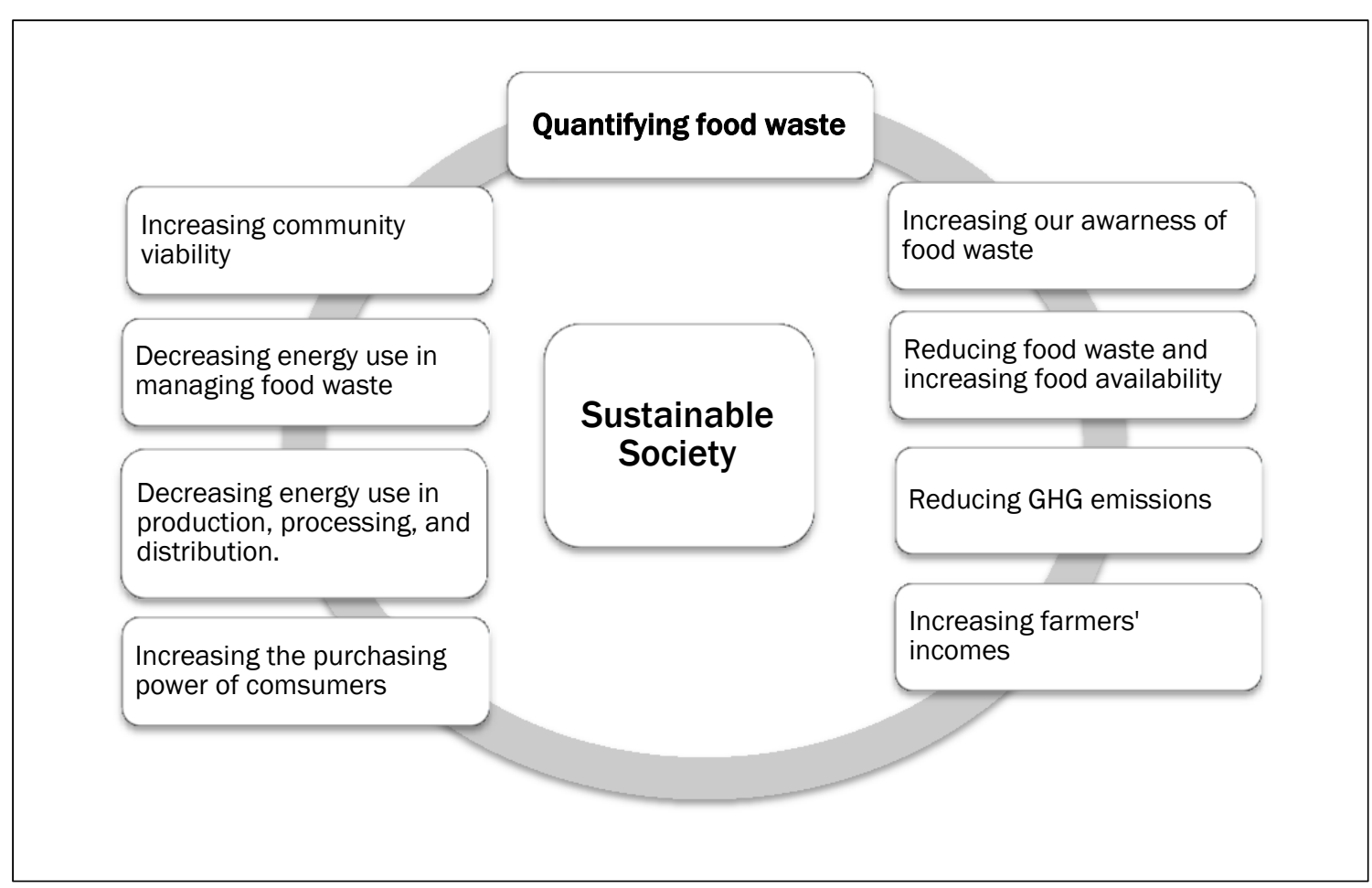


coffee (Statistics Canada, 2003, 2010a). Although the consumption of fruit and vegetables has fluctuated slightly over the past 48 years, the overall trend has been positive. The consumption of most products increased, except for red meat, poultry, spirits (alcohol), and soft drinks. Consumption of red meat has been declining since 1989 (Statistics Canada, 2009). The average consumption of red meat during the period from 1961 to 2086 was $67.2 \mathrm{lb}$. (30.5 kg) per person per year, compared with $57.8 \mathrm{lb}$. $(26.2 \mathrm{~kg})$ per person per year from 1986 to 2009. The consumption of red meat continued to decline, falling to $51.6 \mathrm{lb}$. $(23.4 \mathrm{~kg}$ ) per person per year in 2009 , while poultry consumption has increased in the diet since 1986.

The trend in poultry consumption over the past 48 years was also positive. Egg consumption decreased over the past 48 years with a slight fluctuation. Similarly, the amount of dairy products in the Canadian diet has dropped in general. For example, fluid milk consumption has decreased, while the consumption of creams and cheeses has increased. This contributed to a straight-line trend of the average total consumption of dairy products. Fish consumption has been almost constant from 1988 (since data were available) to 2009.

The consumption of total cereals witnessed an almost steady increase over nearly 48 years. Since 1989 , per capita cereal consumption in the diet has risen by $19.6 \mathrm{lb}$. $(8.9 \mathrm{~kg})$ per person. For example, Canadians increased their consumption of rice to a record high of $15.7 \mathrm{lb} .(7.1 \mathrm{~kg})$ per person in 2009. However, rice available for consumption has more than doubled over the past 20 years and peaked in 2009 at $22.31 \mathrm{lb}$. (10.14 kg) per person.

The total amount of oil and fat consumption fell to $39.5 \mathrm{lb}$. $(17.9 \mathrm{~kg})$ per person in 2009. The peak in oil and fat consumption was in 1998 with $47.2 \mathrm{lb}$. (21.4 kg) per person. Sugar and syrup consumption declined significantly over the 48 -year period, from $28.0 \mathrm{lb}$. $(12.7 \mathrm{~kg})$ per person in 1961 to $21.4 \mathrm{lb} .(9.7 \mathrm{~kg})$ per person in 2009 .

Overall, food consumption was projected to increase by 6 percent by 2020 (based on the averages of 2001, 2002, and 2003), up from 882 to 935 lb. (400 to $424 \mathrm{~kg}$ ) per person, excluding eggs and juices (Agriculture and Agri-Food Canada, 2009).

The increase in food consumption can be attributed to food waste, given that, biologically, each person's consumption is limited (Statistics Canada, 2010a). Yet since 1976 the average number of calories available to a Canadian per day has increased by 9 percent (Statistics Canada, 2009). Concomitant with this increase, a significant percentage has been wasted due to spoilage and loss in stores, restaurants, and homes (Statistics Canada, 2010a). However, the increase in food consumption is marked by a high consumption of fruits and vegetables, either fresh or processed in Canada. The trend in consuming more fruits and vegetables was triggered by an increase in awareness of the importance of eating high-quality foods, in other words, food that is more natural and nutritious (Agriculture and Agri-Food Canada, 2009).

\section{Data}

Due to the lack of primary data, we are using the secondary data collected and published in Food Statistics 2009 and Food Statistics 2002 (Statistics Canada, 2003, 2010). The reports provided historical data about food availability for consumption before and after adjusting for food waste for the following major food categories: fruits, vegetables, animal products (including red meat, poultry, eggs, milk, and cheese), cereals, sugar and syrup, oils and fats, and beverages. The specifications used for their calculations are as follows: available fruits and vegetables for consumption were calculated as fresh, processed, dried, and juiced. For dairy products and eggs, the data included available fluid milk, total cheeses, total creams, other dairy products, and eggs. Red meat and poultry data included carcass weight, retail weight, and boneless weight. The available fish for consumption was provided as one figure.

Thus, the reports give two important figures: first, food availability from the Canadian food supply for human use only; and, second, food availability adjusted for waste by accounting for losses in cooking, storage, homes, restaurants, and institutions. To do this, Statistics Canada used "waste factors" provided by the U.S. Department of Agriculture (USDA) (Statistics Canada, 2010a). Waste factors are only estimates (Statistics Canada, 2010a). Losses at other points of the food supply chain have not been quantified. For the sake of this 
study, we used the aggregate food availability data for these food groups: fruit, vegetables, oil, dairy, red meat, fish, and nuts.

Food availability before and after accounting for waste was traced over the past five decades. This paper presents historical data from 1961 to 2009 for all food categories except fish and poultry (see figures 2 and 3). Fish data are available only from 1988 to 2009, and poultry data are available from 1963 to 2009.

We estimated the food waste per person (FWPP) by subtracting the available food for consumption after adjusting for food waste (AFCAAFW) from the available food for consumption before adjusting for food waste (AFCBAFW) (FWPP = AFCBAFW AFCAAFW). Then we calculated the percentage of food waste by dividing the calculated food waste by total available food before adjusting for waste $((\mathrm{FWPP} / \mathrm{AFCBAFW}) \times 100)$. We estimated the food waste at the national level by multiplying the food waste at the individual level by the population estimate for each year $($ FWPP $\times$ population estimate) (see appendix, table 2). In order to increase the awareness of food waste, we calculated the food waste per person per day by weight for each food category (see appendix, table 3). We also included the available food before and after accounting for waste per person over the five decades (table 3). We calculated the food waste at the individual level per day by dividing food waste by 365 (number of days per year) (FWPP each year/365). The per capita income data from 1961 to 2009 were collected from the World Bank. In the section below, we analyze the results.

\section{Results and Discussion}

Food waste increased by 40 percent over the nearly five decades from 1961 to 2009 ((FWPP/yr in 2009 - FWPP/yr in 1961)/FWPP/yr in 1961). There were variable responses among the food groups. The highest percentage of waste was found in vegetables and fruits (fresh and processed), while the lowest percentage was in pulses and nuts, where the waste rate remained almost the same over the five decades. The other food categories with minimal waste variability over time were fish, eggs, and dairy products (figure 2).

In total, the increase in food waste outpaced the increase in available food for consumption over the same period of time (figure 3). We fitted a linear trend line for total vegetables as "available for consumption" and as "waste." Both trend lines are upward, indicating that the increase in food wastes mirrors the increase in the available food for consumption per person over the five-decade period. The figures for total vegetables available for

\section{Figure 2. Food Waste per Person per Year per Food Category (kg)}

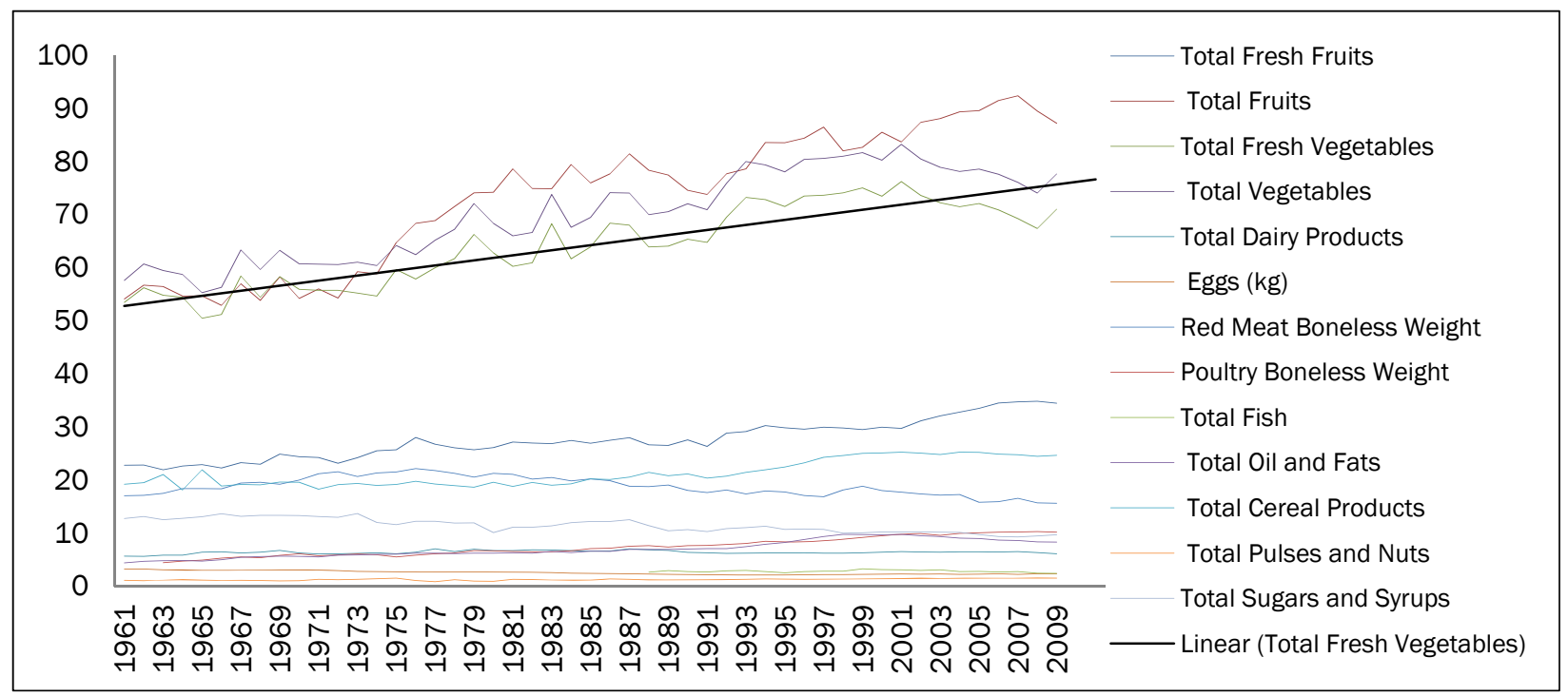

Note: Data on fish have only been available since 1988.

Source: Data from Statistics Canada with calculation by the authors. 


\section{Figure 3. Available Food for Consumption per Person per Year per Food Category (kg)}

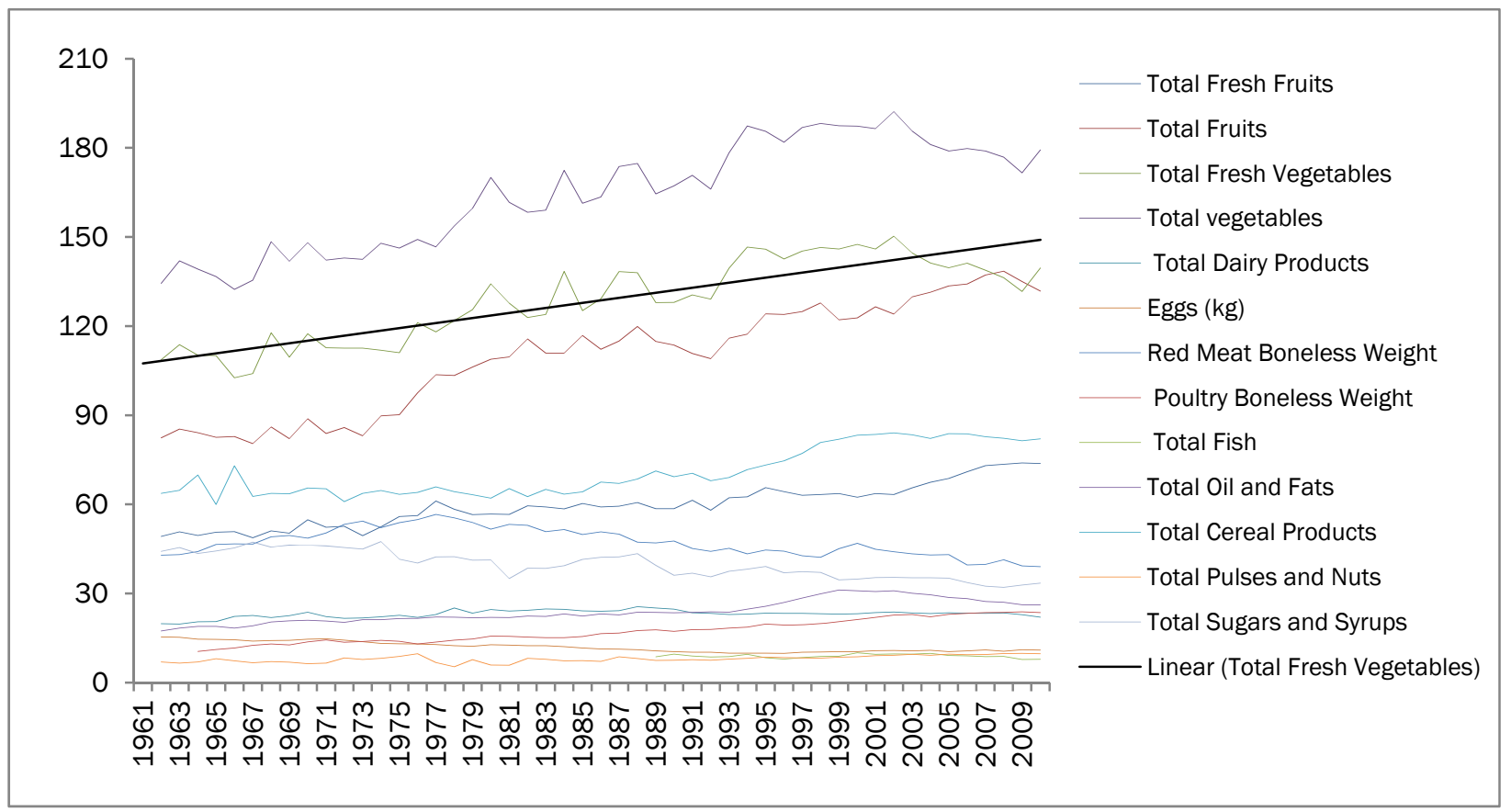

Note: Data on fish have only been available since 1988.

consumption and total wasted vegetables both were significantly higher than their counterparts in the other food categories. Canadians increasingly allocated a smaller percentage of their total expenditure on food and nonalcoholic beverages. For example, in 1961, Canadians allocated 19 percent of their household expenditures to food and nonalcoholic beverages; in 2007, this percentage had declined to 9 percent (Agriculture and Agri-food Canada, 2010). The GDP per capita in current USD also increased over time. The linear trend shows that income grew over time at a steady, upward pace. The significant increase was from 2004 to 2007 (figure 4). Similarly, this increase emulates the increase in food availability and food waste for the same period of time.

The average Canadian spent around CAD1,927 on food and non-alcoholic beverage in 2001. This amount increased to CAD2,198 in 2005 (Statistics Canada, 2010b). The Annual Canada Consumer Expenditure Study by AC Nielsen for Agriculture and Agri-Food Canada (2004) showed that there are a large variety of food and beverage available to Canadian consumers, sufficient to meet ongoing and emerging demands.
Source: Data from Statistics Canada with calculation by the authors.

Data in the five-year review indicate that consumers ate an increasing amount of baked goods and fresh produce, such as whole grain bread and refrigerated bagged salads, and a decreasing amount of canned or prepared foods. This trend in food consumption is due to several factors: the year-round access to fresh food, given the global market; more health-consciousness by Canadians about their food choices; slow population growth $(0.83 \%)$; the changing composition of the population (Agriculture and Agri-Food Canada, 2009); and concern about food safety (Agriculture and Agri-Food Canada, 2007), health and nutrition, quality and freshness (Agriculture and Agri-Food Canada, 2007), convenience (Agriculture and AgriFood Canada, 2007), and variety (Agriculture and Agri-Food Canada, 2007).

Figure 5 illustrates that the growth in real food spending in stores in the last 15 years has kept pace with the growth in disposable income. However, growth in spending on food in restaurants outpaced the growth in disposable income from 1992 to 2004.

The increase in GDP per capita explains the decrease in the share of food expenditure out of 
Figure 4. Canadian GDP per Capita in Current USD

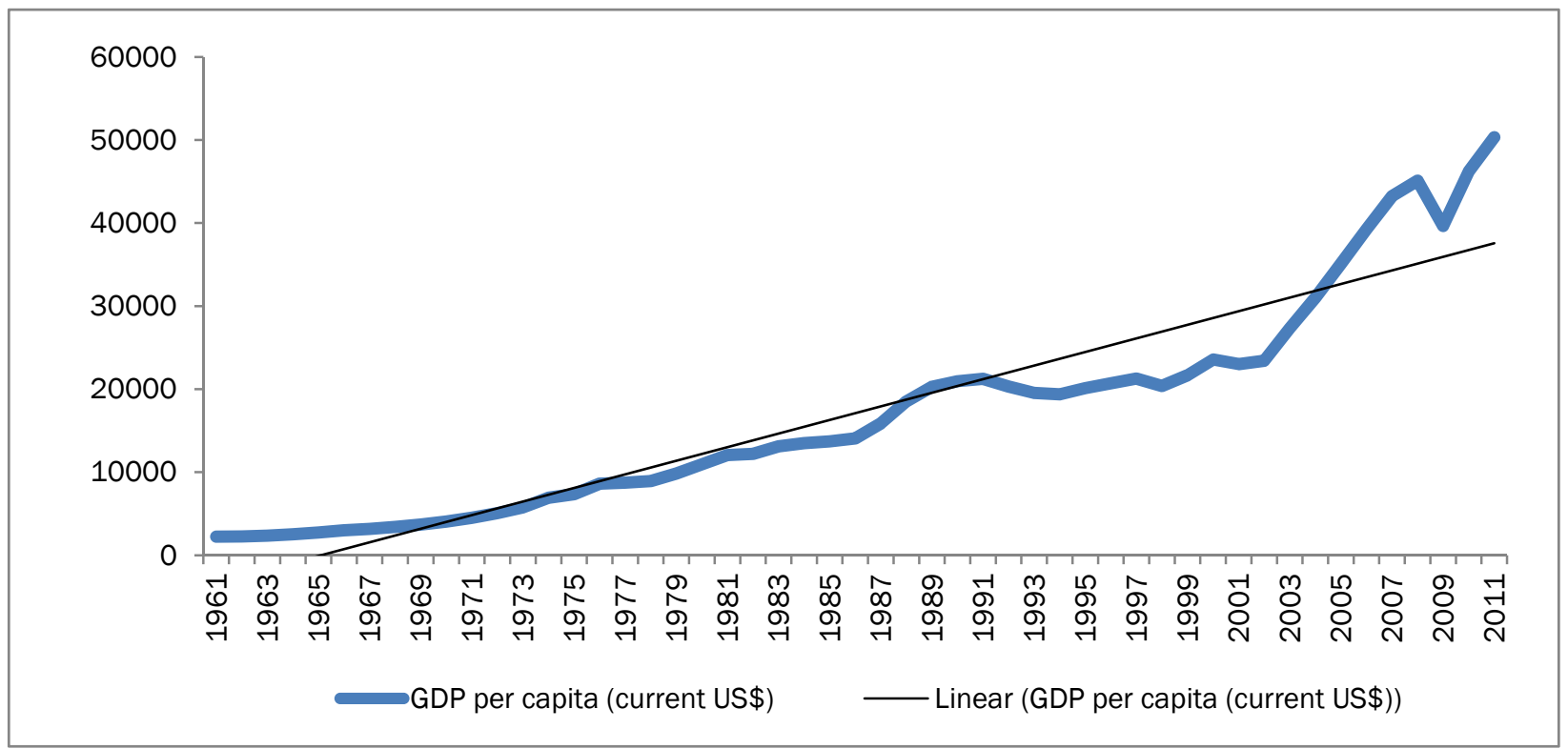

Source: World Bank

the total household expenditure; however, it does not directly explain the high percentage of food

Figure 5. Real Food Spending and Disposable Income of Canadian Consumer, 1992-2005 (constant 1992 CAD)

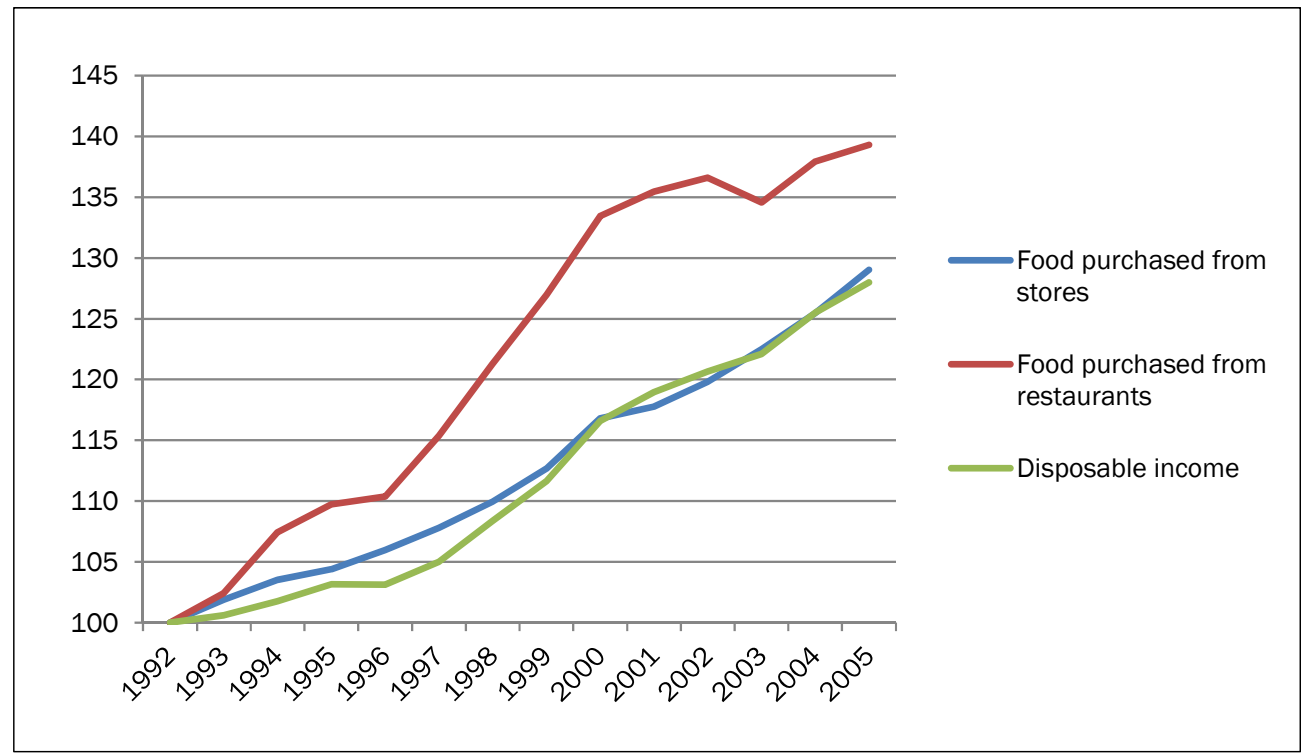

Sources: Statistic Canada:

- Food and nonalcoholic beverage expenditures (retail): Statistics Canada, Personal expenditures on goods and services, CANSIM Table 380-0024.

- Restaurants expenditures: Statistics Canada, Personal Expenditures, Special Tabulation.

- Disposable Income: Statistics Canada, Sector Accounts, CANSIM Table 380-0019.

- CPI: Statistics Canada, CANSIM Table 326-0002. waste. Moving to a higher utility level changes the composition of the consumer diet. Concomitant with the increase in demand for healthy, tasty food, cheap food is no longer a consumer's priority and demand for it decreases. For example, the consumer purchases healthier food, which is usually more expensive than fast food. This explains the increase in spending on food, but not in waste, given that the percentage of income spent on food has declined since 1961. Directly or indirectly, this increase may trigger the 
increase in food waste over time. This relationship is yet to be investigated. This study suggests a need to identify the factors that positively contribute to increased food purchases and waste of scarce resources.

\section{Food Waste and Food Available for Consumption by Food Category}

The estimated average waste in available fresh fruits for consumption per person over the five decades was 46 percent from the total average fresh fruits available for consumption (table 1). Accounting for processed, dried, and juiced fruits, the percent of average waste fruits was 33 percent of total average available fruits. Average waste of fresh vegetables amounted to 50 percent; however, including processed, dried, and juiced vegetables, the average waste accounted for 42 percent of total vegetables available for consumption (table 1 ).

Waste of red meat and poultry were ranked below fruits and vegetables and showed significant waste, even though the consumption of red meat (defined as beef, veal, and pork) declined by $11.5 \mathrm{lb}$. $(5.2 \mathrm{~kg})$ per person over the 20 years up to 2009.

The 40 percent was calculated after accounting for the removal of bones or unavoidable waste. The same applied to poultry. After removing bones, the average waste over the 48 years amounted to 43 percent of poultry available for consumption. The waste in available dairy products for consumption was 28 percent. The waste in fish was less than in red meat and poultry, estimated at 30 percent.

However, fish data have only been available since 1988. The average loss of oil and fat available for consumption to the waste stream was 29 percent during the same period (1988-2009). Total waste in cereal available for consumption was 30 percent. The other products that ranked relatively high in waste magnitude were sugars and syrups, where waste was estimated at 29 percent. Finally, the average waste in pulses and nuts ranked lowest, where the loss was 15 percent of available pulses and nuts for consumption. The amount of average eggs available for human consumption has increased, with the loss estimated at 21 percent (table 1).

Even though these waste factors do not account for waste at the levels of farming, distribution, and processing, the food waste figures — measured as a percentage of available food for

Table 1. Average Available Food for Consumption, Average Waste, and Percentage of Food Waste of Available Food for Consumption by Food Category 1961-2009

\begin{tabular}{|c|c|c|c|c|c|}
\hline \multirow[b]{2}{*}{ Food Category } & \multicolumn{2}{|c|}{$\begin{array}{l}\text { Average Available Food } \\
\text { for Consumption }\end{array}$} & \multicolumn{2}{|c|}{ Average Food Waste } & \multirow{2}{*}{$\begin{array}{l}\text { \% Food Waste of } \\
\text { Available Food } \\
\text { for Consumption }\end{array}$} \\
\hline & Ib. & $\mathrm{kg}$ & Ib. & $\mathrm{kg}$ & \\
\hline Total Fresh Fruits & 131.29 & 59.54 & 60.64 & 27.50 & 46.19 \\
\hline Total Fruits & 241.51 & 109.53 & 161.63 & 73.30 & 66.93 \\
\hline Total Fresh Vegetables & 283.67 & 128.65 & 141.58 & 64.21 & 49.91 \\
\hline Total Vegetables & 362.11 & 164.22 & 154.48 & 70.06 & 42.66 \\
\hline Total Dairy Products & 50.94 & 23.10 & 14.05 & 6.37 & 27.57 \\
\hline Eggs (kg) & 26.46 & 12.00 & 5.53 & 2.51 & 20.94 \\
\hline Red Meat, Boneless Weight & 104.19 & 47.25 & 41.39 & 18.77 & 39.73 \\
\hline Poultry, Boneless Weight & 38.08 & 17.27 & 16.27 & 7.38 & 42.74 \\
\hline Total Fisha & 19.67 & 8.92 & 6.13 & 2.78 & 31.21 \\
\hline Total Oil and Fats & 52.63 & 23.87 & 15.37 & 6.97 & 29.18 \\
\hline Total Cereal Products & 156.03 & 70.76 & 46.81 & 21.23 & 30.00 \\
\hline Total Pulses and Nuts & 17.55 & 7.96 & 2.71 & 1.23 & 15.40 \\
\hline Total Sugars and Syrups & 87.56 & 39.71 & 25.23 & 11.44 & 28.80 \\
\hline Total Waste Per Person Per Year & $1,559.31$ & 707.17 & 687.78 & 311.92 & 44.11 \\
\hline
\end{tabular}


consumption — are high (table 1). Two factors cause concern about waste in the fruit and vegetable category. The obvious factor is the perishability of fresh fruits and vegetables; the second factor is the change in Canadians' food consumption patterns (i.e., healthy dietary trends). Since consumers are the biggest contributors to food waste, increasing consumption of fruit and vegetables will escalate the percentage of waste if consumer behaviors do not change. This is the case particularly if current gaps in the effectiveness of operations conducted along perishable food value chains are not addressed. Hence, the data correlates dietary changes and increases in food waste. The average national amount of food waste over 48 years at retailer and consumer levels for all food groups amounted to 16 billion pounds (seven billion $\mathrm{kg}$ ). Thus the national levels of food production available for consumption were estimated at 41 billion pounds (19 billion $\mathrm{kg}$ ). The percentage of average total food waste at the national level was 37 percent of total food available for consumption (see table 2 in the appendix).

While the actual food waste per person per day varied by food category, the total food wasted at an individual level per day was estimated at $1.65 \mathrm{lb}$. $(0.75 \mathrm{~kg}$ ) (table 3), or $49.69 \mathrm{lb}$. (22.54 kg) per person month. The average available food for consumption per person per day was estimated at $4.27 \mathrm{lb}$. (1.94 kg), or $129 \mathrm{lb} .(58 \mathrm{~kg}$ ) per person per month. Theoretically, three adults wasted a monthly amount $(49.69 \mathrm{lb} . \times 3=149.07 \mathrm{lb}$., or $22.54 \mathrm{~kg} \times 3=67.62 \mathrm{~kg}$ ) that could feed one adult.

The energy costs of food waste are threefold: (1) energy used to produce, process, and distribute the food; (2) energy used for transportation to haul food waste; and (3) energy used to convert food waste to another product, such as compost.

Wasting half the produced food means wasting half of the energy used for its production. This result raises a warning, especially with the current efforts to find ways to decrease energy consumption. Food waste also reduces the availability of food to those who need it.

The answer to the food-waste problem lies in prevention. The benefits of preventing food waste are also threefold: (1) food security is increased; (2) the amount of energy required to manage food waste is reduced; and (3) GHG emissions are decreased.

Even when accounting for a margin of error, this amount of waste is still high. The waste factors used in this report are cumulative factors representing waste in each food category at an aggregate level. Had we had the waste factor for each food group at each point in the food supply chain, such as for the farmer, producer, distributer, and consumer, we could have presented a more accurate picture of how much each agent is contributing individually to this waste. At an aggregate level, food waste accounted for 40 percent of food available for consumption. As we mentioned earlier, these estimates of food waste are at the consumer and retailer levels and do not include waste at the farmer and processor levels.

Assuming a recovery rate of 50 percent of food waste, we could save approximately 20 percent of available food for consumption just from saving food at the consumer and retailer levels. Had we been successful in quantifying food waste along all agents in the food supply chain, the percent of saved food could be much higher. The positive relationship between consumption and food waste might be the outcome of using a waste factor as a percentage of the total consumption. It is difficult to make a comparison with the UK or U.S. since data derivation methods vary. Collaboration among these countries to standardize the methodology of estimating food waste could be translated into a broad data set to view the problem globally.

\section{Recommendations}

There are many food system stakeholders who could be involved in the process of quantifying food waste. Their actions are interrelated and must be analyzed as a whole. Analysis starts with farmers and ends with consumers; they, and everyone in between, play a part in generating food waste. The reasons for each agent's generation of food waste are case-specific. Therefore, the methodologies used to quantify food waste must be able to accommodate the role of each agent. Other agents who sometimes play key but hidden roles in the food system are policy makers and educators. That said, variable methods for quantifying food waste 
at each point are needed to differentiate the causes of food waste.

Data used in this study are not sufficient. We rearranged and recalculated the data to fit our purpose in highlighting the dearth of food waste data. Unlike Canada, other countries such as the UK and the U.S. have taken further steps to measure food waste. To overcome the shortcomings of the data in Canada, launching a pilot study in one area or region that can be replicated in other regions could serve as a first step. The goal is to quantify food waste along the food supply chain, from farmer to consumer. Then these primary data will serve to articulate the obstacles to quantifying food waste and the potential to overcome these obstacles.

Once the data are available, an economic model could be built and the actions of all agents could be analyzed and monitored in relation to other agents in the economy, as well as in relationship to each other. This model will help elucidate each agent's role, identify its contribution to food waste, and highlight the internalized externality of food waste that has been paid by society. In the long run, identifying these factors would help prevent food waste. Based on the specification of the Canadian food system, methods or policies to prevent food waste could be designed without compromising food safety. According to the finding of how much food is wasted and why, a recovery rate could be calculated. It is essential to translate these numbers into energy and GHG figures to be used in increasing awareness of the costs of food waste. Lastly, these data will serve to monitor and evaluate the effectiveness of new or modified policies and the functionality of the food value chain.

\section{Conclusion}

Few Canadian studies have addressed the issue of food waste at the national or provincial level. Little quantitative research has been conducted on the true economic and environmental impacts of food waste in Canada. Nevertheless, there is considerable food waste occurring along the entire food supply chain. It is costly to neglect areas where food waste occurs. Therefore, attention should be expanded to understand the problem and the factors that aggravate the problem. Addressing these factors in the context of current policy may help prevent food waste and reduce the problem. In order to effectively do so, the perception of food waste has to be expanded from management to preventative policy. Ultimately, quantifying food waste would need to be a "must" in order to prevent it.

This investigation suggests the value of modifying Canada's food system policy. This requires that there be systematic data available based on reliable data sources, and/or indicators that can be monitored in a timely fashion. Lastly, as a major stakeholder, government must monitor and support efforts to create an efficient food system with minimal food waste.

\section{Acknowledgement}

The authors want to thank Dr. Lorna Michael Butler, Iowa State University, for her insights and assistance in reviewing the paper.

\section{References}

Agriculture and Agri-food Canada. (2007, November). Consumer perceptions of food safety and quality: $A$ closer look at the 2006 results. Presentation at the Making Choices: Consumers and Their Impact on Canada's Agriculture and Food, Agriculture Institute of Canada Conference, Edmonton, Canada.

Agriculture and Agri-food Canada. (2010). The Canadian consumer: Behaviour, attitudes and perceptions toward food products (Market Analysis Report by the International Market Bureau). Ottawa: Author.

Broughton, M., Estergaard, K., Foo, G., Lefebrve, L., Lutz, H., Macdonald, J.,...Verduyn, I. (2006). The cost of eating in BC: Annual Report 2006. Vancouver, British Columbia: Dietitians of Canada, BC Region and the Community Nutritionists Council of BC. Retrieved from Dieticians of Canada website: http://www.dietitians.ca

Food and Agriculture Organization of the United Nations [FAO]. (n.d.). SAVE FOOD: Global initiative on food loss and waste reduction. http://www.fao.org/save-food/en/

FAO. (2005). The state of food insecurity in the world 2005. Rome: Author. Retrieved from http://www.fao. org/docrep/008/a0200e/a0200e00.htm 
Garnett, T. (2010). Where are the best opportunities for reducing greenhouse gas emissions in the food system (including the food chain)? Food Policy, 36(Supplement 1), S23-S32. http://dx.doi.org/10.1016/j.foodpol.2010.10.010

Gooch M., Felfel, A., \& Marenick, N. (2010). Food waste in Canada. Guelph, Ontario: George Morris Centre, Value Chain Management Centre. Retrieved from http://www.valuechains.ca

Griffin, M., Sobal, J., \& Lyson, T. A. (2009). An analysis of a community food waste stream. Agriculture and Human Values, 26(1-2), 67-81. http://dx.doi.org/10.1007/s10460-008-9178-1

Gustavsson, J., Cederberg, C., Sonesson, U., van Otterdijk, R., \& Meybeck, A. (2011). Global food losses and food waste: Extent, causes and prevention (Study conducted for the International Congress SAVE FOOD at Interpack2011, Düsseldorf, Germany). Rome: FAO. Retrieved from http://www.fao.org/fileadmin/user upload/ ags/publications/GFL web.pdf

Kerstetter, S., \& Goldberg, M. (2007). A review of policy options for increasing food security and income security in British Columbia: A discussion paper. Vancouver: British Columbia Provincial Health Services Authority.

Lundqvist, J., de Fraiture, C., \& Molden, D. (2008). Saving water: From field to fork — Curbing losses and wastage in the food chain (SIWI Policy Brief).

Stockholm: Stockholm International Water Institute (SIWI). Retrieved from http://www.siwi.org

Macdonald, N. (2009, November 9). What a waste. Macleans. Retrieved from http://www2.macleans. $\mathrm{ca} / 2009 / 11 / 09 /$ what-a-waste

Monier, V., Mudgal, S., Escalon, V., O’Connor, C., Gibon, T., Anderson, G.,...Morton, G. (2010). Preparatory study on food waste across EU 27: Final Report (Technical report 2010-054). Paris: European Communities. http://10.2779/85947
Parfitt, J., Barthel, M., \& Macnaughton, S. (2010). Food waste within food supply chains: Quantification and potential for change to 2050. Philosophical Transactions of the Royal Society B, 365, 3065-3081. http://dx.doi.org/10.1098/rstb.2010.0126

Statistics Canada. (2003). Food statistics 2002 (Catalogue No. 21-020-X). Ottawa: Minister of Industry.

Statistics Canada. (2009). Human activity and the environment: Annual statistics (Catalog No. 16-201-X). Ottawa: Statistics Canada. Retrieved from http://www.statcan.gc.ca/pub/16-201-x/16-201x2009000-eng.pdf

Statistics Canada. (2010a). Food statistics 2009 (Catalogue No. 21-020-X). Ottawa: Minister of Industry. Retrieved from http://www.statcan.gc.ca/pub/21020-x/21-020-x2009001-eng.pdf

Statistics Canada (2010b). Spending patterns in Canada, 2009 (Catalogue No. 62-202). Retrieved from http://www.statcan.gc.ca/pub/62-202-x/62-202x2008000-eng.pdf

Statistics Canada (2010). Family characteristics, single-earner and dual earner families, by number of children, annual: Annual estimates for census families and individuals, 2004 (CANSIM Table 111-0020). Retrieved from http://www.statcan.gc.ca/pub/11-402$\mathrm{x} / 2010000 /$ chap/pensions/tbl/tbl05-eng.htm

UK Department of International Development [UK DFID]. (2004). Agriculture, bunger and food security (DFID Working Paper 7). London: Author. Retrieved from http://dfid-agricultureconsultation.nri.org/process.htm

Waste Resources and Action Program [WRAP]. (2011, March 22). New report highlights water and carbon impact of wasted food. Retrieved from http://www.wrap.org.uk/content/new-reporthighlights-water-and-carbon-impact-wasted-food

World Bank. (n.d.). Data: Canada. Retrieved from http://data.worldbank.org/country/canada 


\section{Appendix}

Table 2. Population, Total Food Available and Food Wasted at National Level, Canada, 1961-2009

\begin{tabular}{|c|c|c|c|c|c|}
\hline \multirow[b]{2}{*}{ Year } & \multirow[b]{2}{*}{ Population } & \multicolumn{2}{|c|}{$\begin{array}{c}\text { Food Available for } \\
\text { Consumption at National Level }\end{array}$} & \multicolumn{2}{|c|}{$\begin{array}{c}\text { Total Food } \\
\text { Wasted at National Level }\end{array}$} \\
\hline & & $1,000 \mathrm{lb}$. & $1,000 \mathrm{~kg}$ & $1,000 \mathrm{lb}$. & $1,000 \mathrm{~kg}$ \\
\hline 1961 & $18,238,000$ & $23,511,979$ & $10,663,029$ & $9,058,000$ & $4,108,000$ \\
\hline 1962 & $18,583,000$ & $24,790,596$ & $11,242,901$ & $9,762,819$ & $4,427,582$ \\
\hline 1963 & $18,931,000$ & $25,539,114$ & $11,582,364$ & $9,886,369$ & $4,483,614$ \\
\hline 1964 & $19,291,000$ & $25,684,908$ & $11,648,485$ & $9,970,251$ & $4,521,656$ \\
\hline 1965 & $19,644,000$ & $26,311,276$ & $11,932,551$ & $10,089,262$ & $4,575,629$ \\
\hline 1966 & $20,015,000$ & $26,481,169$ & $12,009,600$ & $11,093,629$ & $5,031,124$ \\
\hline 1967 & $20,378,000$ & $28,672,509$ & $13,003,406$ & $10,886,044$ & $4,936,981$ \\
\hline 1968 & $20,701,000$ & $28,311,749$ & $12,839,795$ & $11,631,444$ & $5,275,031$ \\
\hline 1969 & $21,001,000$ & $30,039,021$ & $13,623,139$ & $11,524,895$ & $5,226,710$ \\
\hline 1970 & $21,297,000$ & $29,646,245$ & $13,445,009$ & $11,835,383$ & $5,367,521$ \\
\hline 1971 & $21,962,032$ & $30,584,586$ & $13,870,561$ & $11,935,851$ & $5,413,084$ \\
\hline 1972 & $22,218,463$ & $30,814,806$ & $13,974,969$ & $12,229,971$ & $5,546,472$ \\
\hline 1973 & $22,491,777$ & $31,990,847$ & $14,508,321$ & $12,384,802$ & $5,616,690$ \\
\hline 1974 & $22,807,969$ & $32,291,715$ & $14,644,769$ & $13,079,225$ & $5,931,621$ \\
\hline 1975 & $23,143,275$ & $33,803,393$ & $15,330,337$ & $13,426,195$ & $6,088,977$ \\
\hline 1976 & $23,449,808$ & $34,768,187$ & $15,767,885$ & $13,716,597$ & $6,220,679$ \\
\hline 1977 & $23,725,843$ & $35,497,625$ & $16,098,696$ & $13,958,971$ & $6,330,599$ \\
\hline 1978 & $23,963,203$ & $36,246,403$ & $16,438,278$ & $14,574,353$ & $6,609,684$ \\
\hline 1979 & $24,201,544$ & $37,663,529$ & $17,080,966$ & $14,406,203$ & $6,533,425$ \\
\hline 1980 & $24,515,667$ & $37,252,873$ & $16,894,727$ & $14,482,100$ & $6,567,846$ \\
\hline 1981 & $24,819,915$ & $37,928,633$ & $17,201,194$ & $14,649,320$ & $6,643,682$ \\
\hline 1982 & $25,116,942$ & $38,200,326$ & $17,324,411$ & $15,613,144$ & $7,080,791$ \\
\hline 1983 & $25,366,451$ & $40,095,589$ & $18,183,940$ & $15,145,783$ & $6,868,836$ \\
\hline 1984 & $25,607,053$ & $39,531,827$ & $17,928,266$ & $15,532,687$ & $7,044,302$ \\
\hline 1985 & $25,842,116$ & $40,255,979$ & $18,256,680$ & $16,302,504$ & $7,393,426$ \\
\hline 1986 & $26,100,278$ & $41,968,574$ & $19,033,367$ & $16,627,869$ & $7,540,984$ \\
\hline 1987 & $26,446,601$ & $43,046,203$ & $19,522,087$ & $16,291,334$ & $7,388,360$ \\
\hline 1988 & $26,791,747$ & $42,346,126$ & $19,204,592$ & $16,515,900$ & $7,490,204$ \\
\hline 1989 & $27,276,781$ & $42,904,050$ & $19,457,619$ & $16,961,568$ & $7,692,321$ \\
\hline 1990 & $27,691,138$ & $43,817,741$ & $19,871,991$ & $16,836,124$ & $7,635,431$ \\
\hline 1991 & $28,037,420$ & $43,356,745$ & $19,662,923$ & $18,094,460$ & $8,206,104$ \\
\hline 1992 & $28,371,264$ & $46,238,965$ & $20,970,052$ & $18,892,114$ & $8,567,852$ \\
\hline 1993 & $28,684,764$ & $48,135,707$ & $21,830,253$ & $19,355,315$ & $8,777,921$ \\
\hline 1994 & $29,000,663$ & $49,477,935$ & $22,438,973$ & $19,324,682$ & $8,764,028$ \\
\hline 1995 & $29,302,311$ & $49,383,935$ & $22,396,342$ & $19,874,438$ & $9,013,350$ \\
\hline 1996 & $29,610,218$ & $50,613,872$ & $22,954,137$ & $20,278,014$ & $9,196,378$ \\
\hline 1997 & $29,905,948$ & $51,841,446$ & $23,510,860$ & $20,517,485$ & $9,304,982$ \\
\hline
\end{tabular}

continued 


\begin{tabular}{|c|c|c|c|c|c|}
\hline & & $\begin{array}{l}\begin{array}{c}\text { Food Available } \\
\text { for }\end{array} \\
\text { Consumption at } \\
\text { National Level }\end{array}$ & $\begin{array}{r}\text { Total Food } \\
\text { Wasted at } \\
\text { National Level }\end{array}$ & & \\
\hline Year & Population & $1,000 \mathrm{lb}$. & $1,000 \mathrm{~kg}$ & $1,000 \mathrm{lb}$. & $1,000 \mathrm{~kg}$ \\
\hline 1998 & $30,155,173$ & $52,076,657$ & $23,617,531$ & $20,906,825$ & $9,481,553$ \\
\hline 1999 & $30,401,286$ & $52,915,288$ & $23,997,863$ & $20,981,997$ & $9,515,645$ \\
\hline 2000 & $30,685,730$ & $53,583,595$ & $24,300,950$ & $21,567,607$ & $9,781,228$ \\
\hline 2001 & $31,019,020$ & $54,744,910$ & $24,827,624$ & $21,612,233$ & $9,801,466$ \\
\hline 2002 & $31,353,656$ & $54,885,435$ & $24,891,354$ & $21,659,389$ & $9,822,852$ \\
\hline 2003 & $31,639,670$ & $54,857,289$ & $24,878,589$ & $21,892,914$ & $9,928,759$ \\
\hline 2004 & $31,940,676$ & $55,426,364$ & $25,136,673$ & $22,125,822$ & $10,034,387$ \\
\hline 2005 & $32,245,209$ & $55,961,217$ & $25,379,237$ & $22,298,262$ & $10,112,591$ \\
\hline 2006 & $32,576,074$ & $56,478,684$ & $25,613,915$ & $22,387,860$ & $10,153,225$ \\
\hline 2007 & $32,929,733$ & $56,933,549$ & $25,820,204$ & $22,216,173$ & $10,075,362$ \\
\hline 2008 & $33,319,098$ & $56,364,384$ & $25,562,079$ & $22,922,056$ & $10,395,490$ \\
\hline 2009 & $33,729,690$ & $57,950,707$ & $26,281,500$ & $16,057,921$ & $7,282,504$ \\
\hline Average & $26,051,535$ & $41,249,475$ & $18,707,245$ & $16,006,637$ & $7,259,246$ \\
\hline
\end{tabular}

Source: Data from Statistics Canada with calculations by the authors. 
Table 3. Total Food Waste and Food Consumption per Person per Day and per Year, Canada, 1961-2009

\begin{tabular}{|c|c|c|c|c|c|c|c|c|}
\hline \multirow[b]{2}{*}{ Year } & \multicolumn{2}{|c|}{$\begin{array}{l}\text { Total Wasted Food } \\
\text { Per Person Per Day }\end{array}$} & \multicolumn{2}{|c|}{$\begin{array}{l}\text { Total Wasted Food } \\
\text { Per Person Per Year }\end{array}$} & \multicolumn{2}{|c|}{$\begin{array}{l}\text { Total Available Food } \\
\text { Per Person Per Day }\end{array}$} & \multicolumn{2}{|c|}{$\begin{array}{l}\text { Total Available Food } \\
\text { Per Person Per Year }\end{array}$} \\
\hline & Ib. & kg & Ib. & kg & Ib. & $\mathrm{kg}$ & Ib. & $\mathrm{kg}$ \\
\hline 1961 & 1.37 & 0.62 & 496.68 & 225.25 & 3.53 & 1.60 & $1,289.18$ & 584.66 \\
\hline 1962 & 1.41 & 0.64 & 512.38 & 232.37 & 3.66 & 1.66 & $1,334.05$ & 605.01 \\
\hline 1963 & 1.41 & 0.64 & 515.71 & 233.88 & 3.70 & 1.68 & $1,349.06$ & 611.82 \\
\hline 1964 & 1.41 & 0.64 & 512.49 & 232.42 & 3.65 & 1.65 & $1,331.45$ & 603.83 \\
\hline 1965 & 1.39 & 0.63 & 507.55 & 230.18 & 3.67 & 1.66 & $1,339.41$ & 607.44 \\
\hline 1966 & 1.39 & 0.63 & 504.09 & 228.61 & 3.62 & 1.64 & $1,323.07$ & 600.03 \\
\hline 1967 & 1.50 & 0.68 & 544.39 & 246.89 & 3.85 & 1.75 & $1,407.03$ & 638.11 \\
\hline 1968 & 1.43 & 0.65 & 525.87 & 238.49 & 3.75 & 1.70 & $1,367.65$ & 620.25 \\
\hline 1969 & 1.52 & 0.69 & 553.85 & 251.18 & 3.92 & 1.78 & $1,430.36$ & 648.69 \\
\hline 1970 & 1.48 & 0.67 & 541.15 & 245.42 & 3.81 & 1.73 & $1,392.04$ & 631.31 \\
\hline 1971 & 1.48 & 0.67 & 538.90 & 244.40 & 3.82 & 1.73 & $1,392.61$ & 631.57 \\
\hline 1972 & 1.48 & 0.67 & 537.20 & 243.63 & 3.80 & 1.72 & $1,386.90$ & 628.98 \\
\hline 1973 & 1.50 & 0.68 & 543.75 & 246.60 & 3.90 & 1.77 & $1,422.34$ & 645.05 \\
\hline 1974 & 1.48 & 0.67 & 543.00 & 246.26 & 3.88 & 1.76 & $1,415.81$ & 642.09 \\
\hline 1975 & 1.54 & 0.70 & 565.14 & 256.30 & 4.00 & 1.81 & $1,460.61$ & 662.41 \\
\hline 1976 & 1.57 & 0.71 & 572.55 & 259.66 & 4.06 & 1.84 & $1,482.66$ & 672.41 \\
\hline 1977 & 1.59 & 0.72 & 578.13 & 262.19 & 4.10 & 1.86 & $1,496.16$ & 678.53 \\
\hline 1978 & 1.59 & 0.72 & 582.52 & 264.18 & 4.14 & 1.88 & $1,512.59$ & 685.98 \\
\hline 1979 & 1.65 & 0.75 & 602.21 & 273.11 & 4.26 & 1.93 & $1,556.24$ & 705.78 \\
\hline 1980 & 1.61 & 0.73 & 587.63 & 266.50 & 4.16 & 1.89 & $1,519.55$ & 689.14 \\
\hline 1981 & 1.59 & 0.72 & 583.49 & 264.62 & 4.19 & 1.90 & $1,528.15$ & 693.04 \\
\hline 1982 & 1.59 & 0.72 & 583.24 & 264.51 & 4.17 & 1.89 & $1,520.90$ & 689.75 \\
\hline 1983 & 1.68 & 0.76 & 615.50 & 279.14 & 4.33 & 1.96 & $1,580.65$ & 716.85 \\
\hline 1984 & 1.61 & 0.73 & 591.47 & 268.24 & 4.23 & 1.92 & $1,543.79$ & 700.13 \\
\hline 1985 & 1.65 & 0.75 & 601.06 & 272.59 & 4.27 & 1.94 & $1,557.77$ & 706.47 \\
\hline 1986 & 1.72 & 0.78 & 624.61 & 283.27 & 4.41 & 2.00 & $1,607.97$ & 729.24 \\
\hline 1987 & 1.72 & 0.78 & 628.73 & 285.14 & 4.46 & 2.02 & $1,627.66$ & 738.17 \\
\hline 1988 & 1.68 & 0.76 & 608.07 & 275.77 & 4.33 & 1.96 & $1,580.57$ & 716.81 \\
\hline 1989 & 1.65 & 0.75 & 605.49 & 274.60 & 4.31 & 1.95 & $1,572.91$ & 713.34 \\
\hline 1990 & 1.68 & 0.76 & 612.53 & 277.79 & 4.34 & 1.97 & $1,582.37$ & 717.63 \\
\hline 1991 & 1.65 & 0.75 & 600.49 & 272.33 & 4.24 & 1.92 & $1,546.39$ & 701.31 \\
\hline 1992 & 1.74 & 0.79 & 637.77 & 289.24 & 4.47 & 2.03 & $1,629.78$ & 739.13 \\
\hline 1993 & 1.81 & 0.82 & 658.61 & 298.69 & 4.60 & 2.09 & $1,678.09$ & 761.04 \\
\hline 1994 & 1.83 & 0.83 & 667.41 & 302.68 & 4.67 & 2.12 & $1,706.10$ & 773.74 \\
\hline 1995 & 1.81 & 0.82 & 659.49 & 299.09 & 4.62 & 2.09 & $1,685.33$ & 764.32 \\
\hline 1996 & 1.83 & 0.83 & 671.20 & 304.40 & 4.68 & 2.12 & $1,709.34$ & 775.21 \\
\hline 1997 & 1.85 & 0.84 & 678.06 & 307.51 & 4.75 & 2.15 & $1,733.48$ & 786.16 \\
\hline 1998 & 1.87 & 0.85 & 680.40 & 308.57 & 4.73 & 2.15 & $1,726.96$ & 783.2 \\
\hline 1999 & 1.87 & 0.85 & 687.70 & 311.88 & 4.77 & 2.16 & $1,740.56$ & 789.37 \\
\hline
\end{tabular}




\begin{tabular}{llllccccc}
\hline & \multicolumn{2}{c}{$\begin{array}{c}\text { Total Wasted Food } \\
\text { Per Person Per Day }\end{array}$} & \multicolumn{2}{c}{$\begin{array}{c}\text { Total Wasted Food } \\
\text { Per Person Per Year }\end{array}$} & $\begin{array}{c}\text { Total Available Food } \\
\text { Per Person Per Day }\end{array}$ & \multicolumn{2}{c}{$\begin{array}{c}\text { Total Available Food } \\
\text { Per Person Per Year }\end{array}$} \\
\cline { 2 - 10 } & lb. & kg & lb. & kg & lb. & kg & lb. & kg \\
\hline 2000 & 1.87 & 0.85 & 683.77 & 310.10 & 4.78 & 2.17 & $1,746.21$ & 791.93 \\
\hline 2001 & 1.90 & 0.86 & 695.30 & 315.33 & 4.84 & 2.19 & $1,764.88$ & 800.4 \\
\hline 2002 & 1.90 & 0.86 & 689.31 & 312.61 & 4.80 & 2.18 & $1,750.53$ & 793.89 \\
\hline 2003 & 1.87 & 0.85 & 684.56 & 310.46 & 4.75 & 2.15 & $1,733.81$ & 786.31 \\
\hline 2004 & 1.87 & 0.85 & 685.42 & 310.85 & 4.75 & 2.16 & $1,735.29$ & 786.98 \\
\hline 2005 & 1.87 & 0.85 & 686.17 & 311.19 & 4.75 & 2.16 & $1,735.49$ & 787.07 \\
\hline 2006 & 1.87 & 0.85 & 684.50 & 310.43 & 4.75 & 2.15 & $1,733.75$ & 786.28 \\
\hline 2007 & 1.85 & 0.84 & 679.87 & 308.33 & 4.74 & 2.15 & $1,728.94$ & 784.1 \\
\hline 2009 & 1.83 & 0.83 & 666.77 & 302.39 & 4.63 & 2.10 & $1,691.65$ & 767.19 \\
\hline Average & 1.85 & 0.84 & 679.58 & 308.20 & 4.71 & 2.13 & $1,718.09$ & 779.18 \\
\hline
\end{tabular}

Source: Data from Statistics Canada with calculations by the authors. 